\title{
The influence of the lexicon on speech read word recognition: Contrasting segmental and lexical distinctiveness
}

\author{
EDWARD T. AUER, JR. \\ House Ear Institute, Los Angeles, California
}

\begin{abstract}
The neighborhood activation model (NAM; P. A. Luce \& Pisoni, 1998) of spoken word recognition was applied to the problem of predicting accuracy of visual spoken word identification. One hundred fiftythree spoken consonant-vowel-consonant words were identified by a group of 12 college-educated adults with normal hearing and a group of 12 college-educated deaf adults. In both groups, item identification accuracy was correlated with the computed NAM output values. Analysis of subsets of the stimulus set demonstrated that when stimulus intelligibility was controlled, words with fewer neighbors were easier to identify than words with many neighbors. However, when neighborhood density was controlled, variation in segmental intelligibility was minimally related to identification accuracy. The present study provides evidence of a common spoken word recognition system for both auditory and visual speech that retains sensitivity to the phonetic properties of the input.
\end{abstract}

The speed and ease with which a spoken word is recognized is a function of both its acoustic-phonetic stimulus properties (e.g., segmental intelligibility) and its lexical properties (e.g., neighborhood density and word frequency; Lahiri \& Marslen-Wilson, 1991; P. A. Luce, 1986; P. A. Luce \& Pisoni, 1998; P. A. Luce, Pisoni, \& Goldinger, 1990; Marslen-Wilson \& Welsh, 1978; McClelland \& Elman, 1986; Norris, 1994). Current spoken word recognition models account for the effects of these two classes of properties within a framework that posits bottom-up activation of multiple word candidates and competition among the active candidates to arrive at the recognition of a single candidate word (P. A. Luce, 1986; P. A. Luce \& Pisoni, 1998; Marslen-Wilson, 1992; McClelland \& Elman, 1986; Norris, 1994). Although the focus of previous research has been, almost exclusively, on words presented auditorily, spoken words can also be accurately recognized solely on the basis of viewing (speechreading, lipreading) the talker. In the present study, the neighborhood activation model (NAM; P. A. Luce, 1986; P. A. Luce \& Pisoni, 1998) was applied to the problem of predicting visual spoken word identification accuracy on the basis of estimates of optical phonetic stimulus and lexical properties. The accuracy of NAM's predictions was tested with data collected in a visual spoken (speech read) word identification experiment.

\footnotetext{
This work was supported by Research Grant R01 DC02107 from the National Institutes on Deafness and Other Communication Disorders, National Institutes of Health. I thank Lynne E. Bernstein, Christopher Kello, and Sven Mattys for their comments on earlier versions of this manuscript and Brian Chaney, Sheri Hithe, and Paula E. Tucker for their helpful advice and assistance. Correspondence concerning this article should be addressed to E. T. Auer, Jr., Spoken Language Processes Laboratory, Department of Communication Neuroscience, House Ear Institute, 2100 West Third Street, Los Angeles, CA 90057 (email: eauer@hei.org).
}

The visible speech stimulus has been characterized as extremely impoverished with respect to phonetic information (Fisher, 1968; Kuhl \& Meltzoff, 1988; Massaro, 1998; Owens \& Blazek, 1985). Accuracy for speech reading sentences is typically observed to be in the range of 5\%-45\% words correct (Rönnberg, 1995; Rönnberg, Samuelsson, \& Lyxell, 1998). The phonetic impoverishment of the visual speech signal has led some investigators to assert that speechreaders must rely on top-down psycholinguistic processes, nonlinguistic context, and strategic processes, such as guessing, to achieve even moderate accuracy (Jeffers \& Barley, 1971; Lyxell \& Rönnberg, 1987; Rönnberg, 1995; cf. Lyxell \& Rönnberg, 1991).

Recent research on visual speech perception in collegeeducated, congenitally deaf adults (e.g., Auer, Bernstein, \& Tucker, 2000; Bernstein, Auer, \& Tucker, 2000; Bernstein, Demorest, \& Tucker, 1998, 2000; Bernstein, Iverson, \& Auer, 1997) has demonstrated that speechreading can be highly accurate (approximately $80 \%$ words correct in isolated sentences) and that variance in individual speechreading performance can be accounted for to a large extent in terms of visual phonetic perception and isolated word recognition (Bernstein, Demorest, \& Tucker, 2000). Auer and Bernstein (1997) reported results of lexical modeling studies suggesting that lexical structure may provide a substantial source of constraint in visual spoken word recognition. Taken together, these current results suggest that perceptual and lexical processes play a prominent role in speech read word recognition. If this assertion is true and if models of auditory spoken word recognition are equally applicable to visual spoken word recognition, then speech reading words would be predicted to be a function of both phonetic stimulus and lexical properties. The present study tests this hypothesis. 
The NAM1 (P. A. Luce, 1986; P. A. Luce \& Pisoni, 1998; P. A. Luce et al., 1990) of auditory spoken word recognition is a computationally explicit model for investigating the combined effects of phonetic stimulus and lexical properties. In the NAM (see P. A. Luce, 1986, and P. A. Luce \& Pisoni, 1998, for a complete description), stimulus input activates a set of acoustic-phonetic patterns in memory, with activation levels of the memory patterns proportional to their perceptual similarity to the input. Acoustic-phonetic input patterns then activate a set of word decision units tuned to the input patterns. Once activated by bottom-up input, these word decision units continuously compute a decision value. The decision values are computed with a frequency-biased, activation-based version of R. D. Luce's (1959) choice rule,

$$
p(\mathrm{ID})=\frac{p\left(\mathrm{~S} \mid \mathrm{S}_{\mathrm{c}}\right) * \text { freq }_{\mathrm{S}}}{\left\{p\left(\mathrm{~S} \mid \mathrm{S}_{\mathrm{c}}\right) * \text { freq }_{\mathrm{S}}\right\}+\sum_{j=1}^{n}\left\{p\left(\mathrm{~N}_{j} \mid \mathrm{S}_{\mathrm{c}}\right) * \text { freq }_{\mathrm{N} j}\right\}},
$$

where $p$ (ID) is the probability of correctly identifying the stimulus word, $p\left(\mathrm{~S} \mid \mathrm{S}_{\mathrm{c}}\right)$ is the support for a stimulus word based on its constituent segments, fre $_{\mathrm{s}}$ is the stimulus word's frequency of occurrence, $p\left(\mathrm{~N}_{j} \mid \mathrm{S}_{\mathrm{c}}\right)$ is the support for the neighbor word $j$ based on the stimulus word's constituent segments, and $f r e q_{\mathrm{N} j}$ is neighbor word $j$ 's frequency of occurrence (see Equation 6 in P. A. Luce \& Pisoni, 1998). The word decision value for a given acousticphonetic pattern is hypothesized to be related to word recognition accuracy, with high word decision values predicting easier word recognition.

NAM makes several predictions regarding spoken word recognition. First, a word's recognition accuracy will be determined not only by the intelligibility of its segments, but also by the number of words sounding similar to it, its neighbors, in the lexicon. That is, given sets of words that comprise different but equally intelligible segments, the words with the most neighbors will be the hardest to recognize. Second, words with high-frequency neighbors will be harder to recognize than words with low-frequency neighbors. Finally, words that occur frequently in the language will be easier to recognize than words that occur less frequently. Empirical evidence supports the basic claims of NAM for auditory word recognition across several different recognition tasks (Cluff \& Luce, 1990; Goldinger, Luce, \& Pisoni, 1989; Goldinger, Luce, Pisoni, \& Marcario, 1992; P. A. Luce, 1986; P. A. Luce, Goldinger, Auer, \& Vitevitch, 2000; P. A. Luce \& Pisoni, 1998; P. A. Luce et al., 1990).

The present study used NAM to predict the influences of variation in optical-phonetic and lexical properties of spoken words on the accuracy of visual-only word identification. NAM's input representations make it a logical choice for application to visual speech stimuli. NAM's input representation can be applied to a variety of perceptual conditions for which phonetic information is im- poverished, including speechreading. NAM's input representations for modeling speech presented in noise have been defined on the basis of confusion matrices that result from perceptual identification of nonsense syllables also presented in noise. To apply the model to any given perceptual condition, all that is necessary is the collection of nonsense syllable confusion data under the relevant conditions. In this study, previously collected speech read nonsense syllable identification data were used to define the input to the model (see below for details). ${ }^{2}$ The output values from NAM (see Equation 1) were used to predict the accuracy of visual spoken word identification. In accord with P. A. Luce and Pisoni's (1998) description, high output values were hypothesized to predict high levels of accuracy. Two different participant groups identified isolated monosyllabic spoken words presented under a visual-alone condition. Both groups were college educated or currently undergraduates; however, in one group the participants had normal hearing, and in the other group the participants had prelingual-onset, profound hearing impairments. The two groups were chosen in order to examine whether predictions of NAM would generalize across a range of individuals who varied on several dimensions, including relative reliance on visual information for day-to-day communication and overall accuracy for speechreading.

A subgoal of the present study was to contrast the effects of segmental intelligibility and neighborhooddensity on word identification. Because NAM combines estimates of segmental intelligibility and neighborhood density into a single output value, these estimates must be computed separately in order to predict their relative contributions to word identification accuracy. The question was whether word identification accuracy can be predicted by segmental intelligibility alone, independent of neighborhood density. To contrast segmental intelligibility and neighborhood density, a semifactorial design (cf. Morrison \& Ellis, 1995) was used for which the numerator and denominator of the NAM decision rule (Equation 1) were separated to generate predictions about word recognition accuracy. Two word sublists were selected on the basis of predicted segmental intelligibility (the numerator of Equation 1) versus neighborhood density (the denominator of Equation 1, without the stimulus word's probability). In the first sublist, word sets were selected for which the members varied on predicted segmental intelligibility (high or low) and were matched on neighborhood density. This set was designed to determine whether a word's segmental intelligibility influences its identification accuracy, when its confusability with its neighbors is controlled. In a second sublist, word sets were selected for which the members varied on predicted neighborhood density (high or low) and were matched on segmental intelligibility. This set was used to examine whether a word's confusability with its neighbors influences its identification accuracy, when the segmental intelligibility of the stimulus word is controlled. 


\section{METHOD}

\section{Participants}

All the participants were screened for the following characteristics: (1) between 18 and 45 years of age; (2) currently enrolled in or graduated from college; (3) no self-reported learning disabilities; (4) self-report of English as a native language; (5) vision 20/30 or better in each eye, as determined with a standard Snellen chart. In addition, deaf participants were screened to have (6) bilateral severe to profound hearing impairment (greater than $80 \mathrm{~dB}$ HL pure tone average across 500,1000, and $2000 \mathrm{~Hz}$ ); (7) self-reported onset of hearing impairment prior to 4 years of age; (8) self-reported use of English as the primary language of the participant's family; (9) average or better performance on a speechreading screening test, as referenced to the appropriate distribution of performance by deaf college-educated adults (Bernstein et al., 1998); and (10) education in a mainstream and/or oral program for 8 or more years. All the participants were paid for their participation and had previously participated in another experiment in our laboratory. ${ }^{3}$

Hearing participants. Twelve participants were recruited from the campuses of University of Southern California, California State University Northridge (CSUN), and the staff of St. Vincent's Hospital, Los Angeles. Seven were female. The group mean age was 22.65 years (range, 18.4-33.9). The speechreading screening test (described above) resulted in a mean percentage of words correct in sentences of 19 (range, 3.11-49.42).

Deaf participants. Thirteen deaf participants were recruited from CSUN. One was dropped owing to a technical malfunction. Of the remaining 12, half were female. The reported ages of the participants at onset of hearing impairment was as follows: birth, 8 participants; 0-1 years, 3 participants; 1-2 years, 1 participant. Ten participants had $90 \mathrm{~dB}$ HL or greater pure tone averages (profound hearing impairment) in both ears. The reported causes of the hearing impairments were unknown, 9 participants, and meningitis, 3 participants. The mean age across the group was 21 years (range, 18.0-24.7). The mean percentage of words correct for speech read screening sentences was 53 (range, 36.96-71.6).

\section{Materials and Procedure}

The stimuli were audiovisual recordings of monosyllabic spoken words stored on laser videodiscs (Bernstein \& Eberhardt, 1986; see the description in Bernstein, Eberhardt, \& Demorest, 1989). The stimuli were spoken by a male talker of American English, seated before a dark background, with his face filling most of the recording frame. He was illuminated by two floodlights at oblique angles to his face and by two fill lights positioned above his head.

One hundred fifty-three consonant-vowel-consonant (CVC) words (the master list) were chosen, and the NAM output value was computed for each word, using Equation 1. Previously collected phoneme identification data were used to estimate phonetic similarity (Bernstein, Coulter, O'Connell, Eberhardt, \& Demorest, 1993; Iverson, Bernstein, \& Auer, 1998). For the consonant identif ication data, the stimuli were recordings of $\mathrm{C}-/ \mathrm{a} /$ syllables. For the vowel identification data, the stimuli were recordings of $/ \mathrm{h} /-\mathrm{V}-/ \mathrm{d} /$ syllables. The talker and stimulus recording conditions for the nonsense syllables were identical to those used in the present word identification study. For the purpose of computing neighborhood statistics, each stimulus word in the master list was compared against 1,506 CVC monosyllabic words drawn from the PhLex on-line lexical database (Seitz, Bernstein, Auer, \& MacEachern, 1998).

The numerator (or segmental intelligibility) was computed as follows. The conditional probability of correctly identifying each of the word's segments was obtained from the nonsense syllable confusion matrices for visible speech segments. By assuming independent probabilities within cells, the conditional probabilities for each of the word's segments were multiplied to calculate an index of the word's overall segmental intelligibility. For example, the segmental intelligibility of the stimulus word bit is the product of the independent conditional probabilities of $p(\mathrm{~b} \mid \mathrm{b}), p(\mathrm{I} \mid \mathrm{I})$, and $p(\mathrm{t} \mid \mathrm{t})$. Words containing easily identified segments were predicted to have higher segmental intelligibility than did words containing poorly identified segments.

The denominator (or neighborhood density) was also computed, using conditional probabilities obtained from nonsense syllable confusion matrices. The probability of identifying each of a stimulus word's neighbors was computed as follows. The conditional probability of identifying each of the neighbor word's segments, given the stimulus word's segments, was obtained from the nonsense syllable confusion matrices. Again, by assuming independent probabilities, the conditional probabilities for each of the neighbor word's segments were multiplied to calculate the neighbor word probability. For example, the probability of the visual neighbor word peel, given the stimulus word bit, $p$ (pil|bit), is the product of the independent conditional probabilities $p(\mathrm{p} \mid \mathrm{b}), p(\mathrm{i} \mid \mathrm{I})$, and $p(1 \mid \mathrm{t})$. In addition, neighbor word probabilities were multiplied by their respective frequency of occurrence in English. ${ }^{4}$ For a given stimulus word, all of its neighbor word probabilities were then summed to arrive at a predicted neighborhood density. Words in higher density lexical neighborhoods were predicted to be more difficult to identify than words in sparse lexical neighborhoods.

The master word list was subdivided into two sublists on the basis of the computed estimates of segmental intelligibility and neighborhood density. One sublist contained two sets of 44 words each. The two sets were matched on segmental intelligibility $[t(86)=0.043$, $p=.96]$ and word frequency $[t(86)=1.92, p=.058]$ and were contrasted on neighborhood density [high vs. low; $t(86)=22.17$, $p<.001]$. This sublist was for examining whether a word's confusability with its neighbors influences its identification accuracy when segmental intelligibility is controlled. The second sublist also contained two sets of 44 words each The sets were matched in neighborhood density $[t(86)=1.218, p=.226]$ and word frequency $[t(86)=1.397, p=.166]$ and were contrasted on segmental intelligibility [high vs. low; $t(86)=23.92, p<.001$ ]. This sublist was for examining whether a word's segmental intelligibility influences its identification accuracy, when its confusability with its neighbors is controlled.

The participants were tested individually in a quiet room. They were seated in front of a computer monitor and were given verbal and written instructions. A research assistant, skilled in sign language, administered verbal instructions to the deaf participants, using simultaneous communication - that is, signs in English word order produced in synchrony with speech. The participants were informed that they would be seeing a series of one-syllable English words presented one at a time. A trial consisted of the video presentation of a single monosyllabic word, followed by the presentation of a prompt on the computer screen for the participants to type their response. The participants were instructed to enter a guess if they were not sure of what the word was. After they entered their response and pressed the Enter key, a short pause preceded the presentation of the next trial.

\section{RESULTS}

Prior to analysis, the responses were corrected for obvious typographic errors, and then all word responses were phonemically transcribed by software look-up. A response was considered correct only if its entire phonemic transcription matched the transcription of the stimulus word. An item analysis was performed to examine the level of identification accuracy over the entire set of stimulus words 
by each participant group. The deaf participants, who were screened to be skilled speechreaders, were more accurate than the randomly selected hearing participants [deaf, the mean percentage correct for items was $28 \%$, the range was $0 \%-100 \%$; hearing, the mean percentage correct for items was $13 \%$, the range was $0 \%-83 \% ; t(304)=5.826$, $p<.001]$. Both participant groups had extremely wide ranges of performance, but mean item identification accuracy was significantly correlated between the two participant groups $(r=.64, p<.01)$. In the deaf participant group, 3 of the 153 items were correctly identified by all of the participants, and 12 items were identified correctly by three quarters or more of the participants.

To assess NAM's predictions for visual spoken word identification accuracy, correlational analyses were performed between NAM output values, estimated segmental intelligibility, neighborhood density, word frequency, and item identification accuracy within each group. Table 1 displays the Pearson correlation coefficients for the hearing and the deaf groups. In both groups, the output of NAM was significantly correlated with the identification accuracy. NAM output values correlated with visual spoken word identification accuracy at levels $(r=.44$ to $r=$ .48) comparable to the correlations reported previously for auditory spoken word identification $(r=.23$ to $r=.47)$ across a range of signal-to-noise ratios (P. A. Luce \& Pisoni, 1998). The estimates of segmental intelligibility were correlated with percentage correct by items only for the hearing participant group. In contrast, the estimates of neighborhood density were correlated with percentage correct by items for both participant groups. Word frequency was correlated with percentage correct by items for the deaf participant group only.

To contrast segmental intelligibility and neighborhood density, the two sublists of stimuli were analyzed. Both subject analyses (repeated measures analysis of variance [ANOVA] ) and item analyses ( $t$ tests) were performed on both sublists. Figure 1 displays the mean percentages of words correct as a function of segmental intelligibility value (high, low) and participant group (deaf, hearing). In the deaf group, identification accuracy did not significantly differ as a function of predicted segmental intelligibility $[$ high $=26 \%$ correct, low $=29 \%$ correct $F(1,11)=1.41$, $p=.260 ; t(86)=0.432, p=.667]$. In the hearing group,

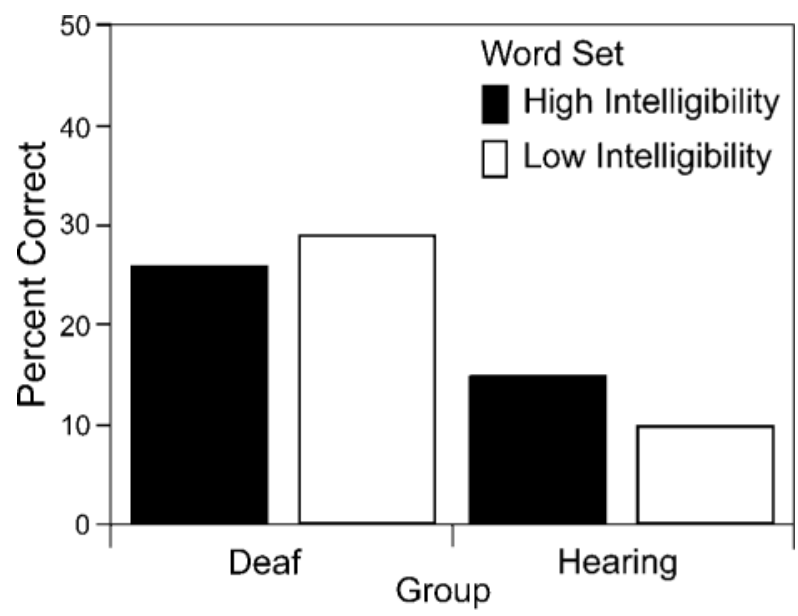

Figure 1. Mean percentage of words correct as a function of segmental intelligibility value (high, low) and participant group (deaf, normal hearing).

identification accuracy was lower for the low segmental intelligibility items analysis (high $=15 \%$ correct, low $=$ $10 \%$ correct). This difference was significant in the subject analysis $[F(1,11)=6.769, p=.025]$, but not in the item analysis $[t(86)=1.18, p=.242]$. A separate ANOVA was performed to examine participant group effects. The deaf group was more accurate than the hearing group $[F(1,22)=$ $33.97, p<.001]$. Furthermore, participant group interacted with the segmental intelligibility factor $[F(1,22)=6.44$, $p=.019$ ].

Figure 2 displays the mean percentages of words correct as a function of neighborhood density (high, low) and participant group (deaf, hearing). In the deaf group, words with many neighbors were more difficult to identify than words with few neighbors [dense $=20 \%$ correct, sparse $=$ $40 \%$ correct $F(1,11)=68.54, p<.001 ; t(86)=3.68, p<$ $.001]$. Likewise, in the hearing participant group, words with many neighbors were more difficult to identify than words with few neighbors [dense $=6 \%$ correct, sparse $=$ $19 \%$ correct; $F(1,11)=63.58, p<.001 ; t(86)=4.12, p<$ $.001]$. A separate ANOVA was performed to examine participant group effects. The main effect of participant group was significant $[F(1,22)=26.87, p<.001]$, and the par-

Table 1

Pearson Correlation Coefficients Between Item Accuracy Data and Variables for Both Participant Groups

\begin{tabular}{lccccc}
\hline \multicolumn{1}{c}{ Measure } & $\begin{array}{c}\text { Percent } \\
\text { Correct }\end{array}$ & $\begin{array}{c}\text { Segmental } \\
\text { Intelligibility }\end{array}$ & $\begin{array}{c}\text { Neighborhood } \\
\text { Density }\end{array}$ & $\begin{array}{c}\text { NAM } \\
\text { Output }\end{array}$ & $\begin{array}{c}\text { Word } \\
\text { Frequency }\end{array}$ \\
\hline 1. Percent correct, hearing & - & $.20^{*}$ & $-.34 * *$ & $.44^{* * *}$ & .14 \\
2. Percent correct, deaf & - & .05 & $-.32^{* *}$ & $.48^{* *}$ & $.28^{* *}$ \\
3. Segmental intelligibility & & - & -.08 & $.38^{* *}$ & -.07 \\
4. Neighborhood density & & & - & $.49^{* *}$ & $.20^{*}$ \\
5. NAM output & & & & - & $.43^{* *}$ \\
6. Word frequency & & & & & - \\
\hline
\end{tabular}

Note-NAM, neighborhood accuracy model. $\quad * p<.05 . \quad * * p<.01$. 


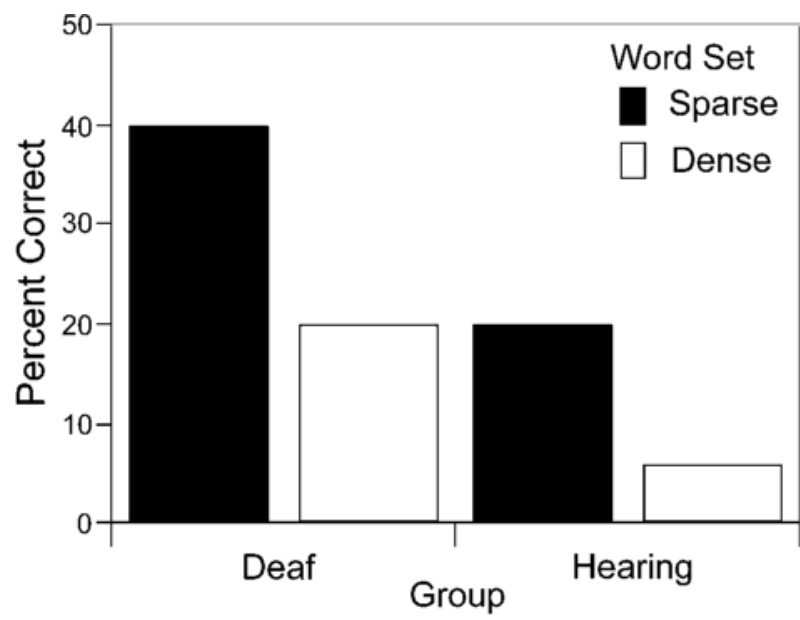

Figure 2. Mean percentage of words correct as a function of stimulus neighborhood density (sparse, dense) and participant group (deaf, normal hearing).

ticipant group $\times$ neighborhood density factor interaction was significant $[F(1,22)=5.62, p=.027]$.

\section{DISCUSSION}

The results of this study demonstrate that the ease of visual spoken word identification is influenced by the number of perceptually similar words in the mental lexicon. This conclusion was supported both by the results of correlation analyses for the entire stimulus set and by the comparisons within the stimulus sublists that focused on the lexical density effect. Just as with auditory spoken word recognition, words in dense neighborhoods were more difficult to identify than words in sparse neighborhoods. Thus, the present results are consistent with contemporary models of auditory spoken word recognition that posit bottom-up activation of multiple word candidates and competition among the active candidates to arrive at the recognition of a single candidate word. An implication of this correspondence across input modalities is that spoken words are recognized via a common spoken word recognition system. The existence of a common spoken word recognition system is also supported by recent fMRI studies demonstrating common cortical regions in the secondary auditory cortex activated during the processing of both auditorily and visually presented spoken words (Bernstein, Auer, et al., 2000; Calvert et al., 1997).

Surprisingly, only minimal evidence was obtained for a segmental intelligibility effect when neighborhood density was controlled. One explanation for this could be that the present stimulus set had a somewhat limited range of estimated segmental intelligibility. These stimuli were chosen from a limited corpus of available recordings, which may not have included an adequate range of segmental intelligibility. In addition, the estimates of segmental intelligibility may have been poorly fit with the abilities of the deaf perceivers. That is, the segmental confusion data were collected from an unscreened group of hearing speechreaders, and not from skilled deaf speechreaders. The latter explanation receives support from the significant correlation of segmental intelligibility with identification accuracy and the significant difference between high and low segmental intelligibility in the subject analysis in the hearing participant group only. Irrespective of the actual explanation(s), a more recent study in our laboratory has demonstrated an effect of stimulus intelligibility with an expanded stimulus set selected using more appropriate estimates of segmental intelligibility (Mattys, Bernstein, \& Auer, in press).

The NAM specifically predicts that neighborhoodeffects obtained in the present study are the result of the perceptual similarity of words (P. A. Luce \& Pisoni, 1998). ${ }^{5}$ Thus, the density of a word's neighborhood is predicted to depend, in part, on the perceptually defined similarity relations among segments in the language, which will vary as a function of the stimulus presentation conditions. Visual speech provides the opportunity for a strong test of this prediction, because it provides information complementary to that available in auditory speech degraded by noise (Breeuwer \& Plomp, 1985; Grant \& Braida, 1991; Grant \& Walden, 1996). Thus, it was hypothesized that if NAM output values depended critically on perceptually defined similarity, confusions obtained for noise-degraded acoustic speech should not correlate with the present visual word identification accuracy.

To test this hypothesis, a previously collected set of confusions for acoustic speech presented in noise (P. A. Luce, 1986) was used as input to NAM. A set of confusions was chosen that roughly matched the visual confusion data on identification accuracy for consonants [visual $=48 \%$ correct; auditory $=51 \%$ correct $;+5 \mathrm{~S} / \mathrm{N}]$ and vowels $[$ visual $=51 \%$ correct; auditory $=67 \%$ correct; $+5 \mathrm{~S} / \mathrm{N}]$. $\mathrm{NAM}_{\text {audio }}$ output values computed with the acoustic confusion data were not significantly correlated with visual word identification accuracy in the hearing group $[r=.046]$ but were correlated for the deaf group $[r=.28, p>.05]$. However, the calculation of Equation 1 includes word frequency, and frequency was correlated with visual word identification scores for the deaf group, but not for the hearing group (see Table 1, last column). To investigate whether the correlation of $\mathrm{NAM}_{\text {audio }}$ was due to the inclusion of frequency in Equation 1, NAM output values were recomputed, leaving word frequency out. In the new analysis, the correlations between identification accuracy and $\mathrm{NAM}_{\text {audio }}$ were no longer significant in either group $[r=-.11$, hearing group; $r=.11$, deaf group], but identification accuracy and $\mathrm{NAM}_{\mathrm{video}}$ remained significant for both participant groups $[r=.33$, hearing group; $r=.24$, deaf group]. This pattern of results supports NAM's prediction that a word's competitor environment depends on stimulus-based similarity.

In conclusion, the results of the present study provide strong evidence of lexical neighborhood effects in the recognition of speech read words. Furthermore, the NAM 
model correctly predicted the pattern of identification accuracy in visual spoken word recognition. These results emphasize the importance of perceptual and lexical processes in speech read word recognition. Finally, the results are interpreted as evidence of a common spoken word recognition system for both auditory and visual speech information that retains sensitivity to stimulus-defined similarity among words in each modality.

\section{REFERENCES}

ANDREwS, S. (1989). Frequency and neighborhoodeffects on lexical access: Activation or search? Journal of Experimental Psychology: Learning, Memory, \& Cognition, 15, 802-814.

ANDREWS, S. (1997). The effect of orthographic similarity on lexical retrieval: Resolving neighborhoodconflicts. Psychonomic Bulletin \& Review, 4, 439-461.

Auer, E. T., JR., \& Bernstein, L. E. (1997). Speechreading and the structure of the lexicon: Computationally modeling the effects of reduced phonetic distinctiveness on lexical uniqueness. Journal of the Acoustical Society of America, 102, 3704-3647.

Auer, E. T., Jr., Bernstein, L. E., \& Tucker, P. E. (2000). Is subjective word familiarity a meter of ambient language? A natural experiment on effects of perceptual experience. Memory \& Cognition, 28, 789-797.

Bernstein, L. E., Auer, E. T., Jr., Moore, J. K., Ponton, C., Don, M., \& Singh, M. (2000, April). Does auditory cortex listen to visible speech? Poster presented at Cognitive Neuroscience Society, San Francisco.

Bernstein, L. E., Auer, E. T., Jr., \& Tucker, P. E. (2000). Can speechreading of sentences be improved by short-term training/practice? Results from deaf and hearing adults trained with speechreading alone and with a vibrotactile speech aid. Journal of Speech, Language, \& Hearing Research, 44, 5-18.

Bernstein, L. E., Coulter, D. C., O'Connell, M. P., Eberhardt, S. P., \& Demorest, M. E. (1993). Vibrotactile and haptic speech codes. In A. Risberg, S. Felicetti, G. Plant, \& K.-E. Spens (Eds.), Proceedings of the Second International Conference on Tactile Aids, Hearing Aids, \& Cochlear Implants (pp. 57-70). ISSN 0280-9850.

Bernstein, L. E., Demorest, M. E., \& Tucker, P. E. (1998). What makes a good speechreader? First you have to find one. In R. Campbell, B. Dodd, \& D. Burnham (Eds.), Hearing by eye: II. The psychology of speechreading and auditory-visual speech (pp. 211-228). Hove, U.K.: Psychology Press.

Bernstein, L. E., Demorest, M. E., \& Tucker,P. E. (2000). Speech perception without hearing. Perception \& Psychophysics, 62, 233-252.

Bernstein, L. E., \& EBerhardt, S. P. (1986). Johns Hopkins Lipreading Corpus I-II: Disc I [Videodisk]. Baltimore: Johns Hopkins University.

Bernstein, L. E., Eberhardt, S. P., \& Demorest, M. E. (1989), Singlechannel vibrotactile supplements to visual perception of intonation and stress. Journal of the Acoustical Society of America, 85, 397-405.

Bernstein, L. E., Iverson, P., \& Auer, E. T., JR. (1997). Elucidating the complex relationships between phonetic perception and word recognition in audiovisual speech perception. Proceedings of the ESCA/ESCOP Workshop on Audio-Visual Speech Processing (pp. 8992). ISSN 1018-4554.

Breeuwer, M., \& Plomp, R. (1985). Speechreading supplemented with formant-frequency information from voiced speech. Journal of the Acoustical Society of America, 77, 314-317.

Calvert, G. A., Bullmore, E. T., Brammer, M. J., Campbell, R., Williams, C. R., McGuire, P. K., Woodruff, P. W. R, Iversen S. D., \& David, A. S. (1997). Activation of auditory cortex during silent lipreading. Science, 276, 593-596.

CARroll, J. B. (1970). An alternative to Julliand's usage coefficient for lexical frequencies, and a proposal for a standard frequency index (SFI). Computer Studies in Humanities \& Verbal Behavior, 3, 61-65.

Cluff, M. S., \& LuCE, P. A. (1990). Similarity neighborhoodsof spoken two syllable words: Retroactive effects on multiple activation. Journal of Experimental Psychology: Human Perception \& Performance, 16, 551-563.

Fisher, C. G. (1968). Confusions among visually perceived consonants. Journal of Speech \& Hearing Research, 11, 796-804.

Forster, K. I., \& SHEN, D. (1996). No enemies in the neighborhood:Absence of inhibitory neighborhood effects in lexical decision and semantic categorization. Journal of Experimental Psychology: Learning, Memory, \& Cognition, 22, 696-713.

Goldinger, S. D., Luce, P. A., \& Pisoni, D. B. (1989). Priming lexical neighbors of spoken words: Effects of competition and inhibition. Journal of Memory \& Language, 28, 501-518.

Goldinger, S. D., Luce, P. A., Pisoni, D. B., \& Marcario, J. K. (1992). Form-based priming in spoken word recognition: The roles of competitive activation and response bias. Journal of Experimental Psychology: Learning, Memory, \& Cognition, 18, 1211-1238.

Grant, K. W., \& Braida, L. D. (1991). Evaluating the articulation index for auditory-visual input. Journal of the Acoustical Society of America, 89, 2952-2960.

GRANT, K. W., \& WALDEN, B. E. (1996). Spectral distribution of prosodic information. Journal of Speech \& Hearing Research, 39, 228-238.

Iverson, P., Bernstein, L. E., \& Auer, E. T., Jr. (1998). Phonetic perception and word recognition. Speech Communication, 26, 45-63.

JefFers, J., \& BARLEY, M. (1971). Speechreading (lipreading). Springfield, IL: Thomas.

KuČERA, H., \& Francis, W. (1967). Computational analysis of presentday American English. Providence, RI: Brown University Press.

Kuhl, P. K., \& Meltzoff, A. N. (1988). Speech as an intermodal object of perception. In A. Yonas (Ed.), Perceptual development in infancy (Vol. 20, pp. 235-266). Hillsdale, NJ: Erlbaum.

LAHIRI, A., \& MARSLEN-Wilson, W. (1991). The mental representation of lexical form: A phonological approach to the recognition lexicon. Cognition, 38, 245-294.

LuCE, P. A. (1986). Neighborhoods of words in the mental lexicon (Research on Speech Perception, Tech. Rep. No. 6). Bloomington:Indiana University, Department of Psychology, Speech Research Laboratory.

Luce, P. A., Goldinger, S. D., Auer, E. T., Jr., \& Vitevitch, M. S. (2000). Phonetic priming, neighborhoodactivation, and PARSYN. Perception \& Psychophysics, 62, 615-625.

Luce, P. A., \& Pisoni, D. B. (1998). Recognizing spoken words: The neighborhood activation model. Ear \& Hearing, 19, 1-36.

Luce, P. A., Pisoni, D. B., \& Goldinger, S. D. (1990). Similarity neighborhoods of spoken words. In G. T. M. Altmann (Ed.), Cognitive models of speech processing (pp. 122-147). Cambridge, MA: MIT Press.

Luce, R. D. (1959). Individual choice behavior. New York: Wiley.

LyXeLl, B., \& RöNNBERG, J. (1987). Guessing and speechreading. British Journal of Audiology, 21, 13-20.

LYXELL, B., \& RöNNBERG, J. (1991). Visual speech processing: Worddecoding and word-discrimination related to sentence-based speechreading and hearing impairment. Scandinavian Journal of Psychology, 32, 9-17.

MARSLEN-Wilson, W. D. (1992) Access and integration:Projecting sound onto meaning. In W. D. Marslen-Wilson (Ed.), Lexical representation and process (pp. 3-24). Cambridge, MA: MIT Press.

Marslen-Wilson, W. D., \& Welsh, A. (1978). Processing interactions and lexical access during word recognition in continuous speech. Cognitive Psychology, 10, 29-63.

Massaro, D. (1998). Perceiving talking faces: From speech perception to a behavioral principle. Cambridge, MA: MIT Press, Bradford Books.

Mattys, S., Bernstein, L. E., \& Auer, E. T., Jr. (in press). Stimulusbased lexical distinctiveness as a general word-recognition mechanism. Perception \& Psychophysics.

McClelland, J. L., \& Elman, J. L. (1986). The TRACE model of speech perception. Cognitive Psychology, 18, 1-86.

Morrison, C. M., \& Ellis, A. W. (1995). Roles of word frequency and age of acquisition in word naming and lexical decision. Journal of Experimental Psychology: Learning, Memory, \& Cognition, 21, 116-133.

NorRIS, D. (1994). Shortlist: A connectionist model of continuous word recognition. Cognition, 52, 189-234. 
Owens, E., \& BLAzeK, B. (1985). Visemes observed by hearing-impaired and normal-hearing adult viewers. Journal of Speech \& Hearing Research, 28, 381-393.

Rönnberg, J. (1995). Perceptual compensation in the deaf and blind: Myth or reality? In R. A. Dixon \& L. Bäckman (Eds.), Compensating for psychological deficits and declines (pp. 251-274). Mahwah, NJ: Erlbaum.

RönNberg, J., SAmuelsson, S., \& LyXell, B. (1998). Conceptual constraints in sentence-based lipreading in the hearing-impaired. In R. Campbell, B. Dodd, \& D. Burnham (Eds.), Hearing by eye: II. The psychology of speechreading and auditory-visual speech (pp. 143-153). Hove, U.K.: Psychology Press.

Seitz, P. F., Bernstein, L. E., Auer, E. T., Jr., \& MacEachern, M. E. (1998).PhLex (phonologicallytransformable lexicon): A 35,000-word computer readable pronouncing American English lexicon on structural principles, with accompanying phonological transformations, and word frequencies. Los Angeles: House Ear Institute.

\section{NOTES}

1. Most current models share the assumption that word recognition is a function of segmental intelligibility and lexical properties. In the present paper, NAM is the focus, because its computational instantiation provides the most straightforward set of tools for generating predictions relevant to the hypotheses tested.

2. The present implementation of NAM differed from the model described in P. A. Luce and Pisoni (1998) in two other ways. First, in the present study, both initial and final consonants were modeled using identification data from initial consonants. This was a practical modification based on the available identification data. Second, there was no modeling of consonant addition or deletion. Unlike P. A. Luce and Pisoni, the present stimulus set comprised only consonant-vowel-consonant words.

3. All of the participants in the present experiment had recently participated in another visual spoken word experiment in our laboratory. Owing to the availability of a limited number of previously recorded word stimuli, $82 \%$ of the tokens had been previously encountered by the participants in the days prior to the present study. The number of encounters ranged from one to three times $(20.3 \%=$ once, $37.3 \%=$ twice, and $24.2=$ three times). This repetition potentially presented a problem for interpreting the present data, because the previous experience could have inflated identification scores. Pearson correlations were performed on the total stimulus set of 153 items to examine the relationship between the number of previous repetitions and the obtained identification scores (deaf participants, $r=-.033$; hearing participants, $r=.027$ ).

4. Frequencies in the modeling were transformed (see Carroll, 1970) using $f\left(p_{i}\right)+40+10 *\left(\ln p_{i}+10\right)$, where $p_{i}$ is the frequency of word $i$ in Kučera and Francis (1967), expressed as a proportion (i.e., $p_{i}$ is the frequency of word $i$ divided by the sum the frequencies of all the words in PhLex; Seitz et al., 1998).

5 . For both heard and seen spoken words, identification is more difficult in a dense neighborhood. However, the evidence from printed word recognition in English suggests exactly the opposite result (Andrews, 1989, 1997; Forster \& Shen, 1996).

(Manuscript received June 15, 2000;

revision accepted for publication June 1, 2001.) 